\title{
In Vivo Analysis of Fas/FasL Interactions in HIV-infected Patients
}

\author{
Andrew D. Badley, ${ }^{\star}$ David H. Dockrell,§ Alicia Algeciras, ${ }^{\star}$ Steve Ziesmer, ${ }^{\ddagger}$ Alan Landay, Michael M. Lederman, ${ }^{\star \star}$ \\ Elizabeth Connick, ${ }^{\ddagger \ddagger}$ Harold Kessler, Daniel Kuritzkes, ${ }^{\ddagger}$ David H. Lynch, ${ }^{\S}$ Patrick Roche, ${ }^{\ddagger}$ Hideo Yagita, \\ and Carlos V. Paya ${ }^{\star \star \star *}$ \\ $*$ Department of Immunology, ${ }^{\ddagger}$ Department of Pathology, and ${ }^{\S}$ Division of Infectious Diseases, Mayo Clinic, Rochester, Minnesota 55905; \\ ${ }^{\|}$Rush Presbyterian - St. Luke's Medical Center, Chicago, Illinois 60612; **Case Western Reserve University, Cleveland, Ohio 44106; \\ ¥University of Colorado Health Sciences Center, Denver, Colorado 80302; $\$ \$$ Department of Immunobiology, Immunex Corporation, \\ Seattle, Washington 98101; and ${ }^{|l|}$ Department of Immunology, Juntendo University School of Medicine, Bunkyo-ku, Tokyo 113, Japan
}

\begin{abstract}
Recent insights into the pharmacological control of HIV replication and the molecular mechanisms of peripheral $\mathrm{T}$ cells homeostasis allowed us to investigate in vivo the mechanisms mediating $\mathrm{T}$ cell depletion in HIV-infected patients. Before the initiation of highly active antiretroviral therapy (HAART), a high degree of lymphoid tissue apoptosis is present, which is reduced upon HAART initiation $(P<$ 0.001 ) and directly correlates with reduction of viral load and increases of peripheral T lymphocytes $(P<0.01)$. Because Fas/FasL interactions play a key role in peripheral $\mathrm{T}$ lymphocyte homeostasis, we investigated the susceptibility to Fas-mediated apoptosis in peripheral $\mathrm{T}$ lymphocytes and of FasL expression in lymphoid tissue before and during HAART. High levels of Fas-susceptibility found in peripheral CD4 T lymphocytes before HAART were significantly reduced after HAART, coinciding with decreases in viral load $(P=0.018)$ and increases in peripheral CD4 T lymphocyte counts $(P<0.01)$. However, the increased FasL expression in the lymphoid tissue of HIV-infected individuals was not reduced after HAART. These results demonstrate that lymphoid tissue apoptosis directly correlates with viral load and peripheral $\mathrm{T}$ lymphocyte numbers, and suggest that HIV-induced susceptibility to Fas-dependent apoptosis may play a key role in the regulation of $\mathrm{T}$ cell homeostasis in HIV-infected individuals. (J. Clin. Invest. 1998. 102:7987.) Key words: HIV - CD4 T cells - FasL - apoptosis • highly active retroviral therapy
\end{abstract}

\section{Introduction}

Although progress in the in vivo study of HIV pathogenesis has established an association between $\mathrm{T}$ cell depletion and the degree of HIV replication, the precise mechanism(s)

A.D. Badley and D.H. Dockrell contributed equally to this work.

Address correspondence to Carlos V. Paya, Mayo Clinic, 200 First Street SW, Guggenheim 501, Rochester, MN 55905. Phone: $507-$ 284-3747; FAX: 507-284-3757; E-mail: paya@mayo.edu A.D. Badley's current address is Division of Infectious Diseases, Ottawa General Hospital, Ottawa, Ontario K1H 8M5, Canada.

Received for publication 30 December 1997 and accepted in revised form 23 April 1998.

J. Clin. Invest.

(C) The American Society for Clinical Investigation, Inc. 0021-9738/98/07/0079/09 \$2.00

Volume 102, Number 1, July 1998, 79-87

http://www.jci.org whereby HIV replication influences T cell homeostasis still remains to be identified (1). An array of processes have been identified in vitro, as potential causes of $\mathrm{T}$ cell death in the context of HIV infection; however, none have been clearly demonstrated to be present or functional in vivo, including $\mathrm{T}$ cell apoptosis (2).

Recent developments in the understanding of the physiology of peripheral $\mathrm{T}$ lymphocyte homeostasis have identified defined ligands and receptors such as Fas/FasL as a key step in controlling peripheral $\mathrm{T}$ cell turnover under physiological conditions (3-7). Whereas naive resting Fas(+) T lymphocytes are resistant to Fas-mediated apoptosis, their activation by antigen presentation or pharmacological compounds renders them susceptible to apoptosis (8). Accumulating information supports the concept that circulating $\mathrm{T}$ lymphocytes from HIVinfected patients are in an enhanced state of immune activation, which, in fact, may translate into the observed increased levels of ex vivo spontaneous $\mathrm{T}$ cell apoptosis, activation-induced T cell apoptosis, and T cell susceptibility to Fas-dependent apoptosis (9-12). Although the exact mechanisms leading to this state of abnormal and enhanced peripheral $\mathrm{T}$ cell activation is currently unknown, HIV proteins and the balance of HIVinduced cytokines or chemokines may all play a role (13-14). However, it is still unclear whether this enhanced and abnormal state of $\mathrm{T}$ cell activation and susceptibility to apoptosis, present in HIV-infected individuals with high viral load, plays any role in disrupting $\mathrm{T}$ cell homeostasis. The current availability of pharmacologic agents that effectively and rapidly interfere with HIV replication provide a unique opportunity to investigate the role of mechanisms postulated in vitro to lead to $\mathrm{T}$ cell depletion in HIV infection, such as $\mathrm{T}$ cell apoptosis. Specifically, it is possible to investigate whether the enhanced state of peripheral $\mathrm{T}$ cell activation, and hence, susceptibility to apoptosis, correlates directly with lymphoid tissue apoptosis and with defined molecular mechanisms that control peripheral T cell homeostasis.

Using a well defined cohort of HIV-infected individuals studied before administration of highly active antiretroviral therapy (HAART), ${ }^{1}$ we demonstrate a significant increase in the degree of basal lymphoid tissue apoptosis and of susceptibility to Fas-dependent apoptosis in peripheral T cells. After initiation of HAART, there is a rapid reduction in lymphoid tissue apoptosis and the susceptibility of peripheral CD4 T cells to Fas-mediated apoptosis, both of which correlate with a significant decrease in viral load and an increase in peripheral $\mathrm{T}$ cells. Interestingly, FasL expression in lymphoid tissue,

1. Abbreviations used in this paper: HAART, highly active antiretroviral therapy; TUNEL, terminal deoxynucleotide UTP transferase. 
which is significantly increased in HIV-infected individuals, remains elevated despite HAART. Altogether, these studies establish a correlation between the degree of lymphoid tissue apoptosis, $\mathrm{T}$ cell homeostasis, and the modulation of a defined molecular mechanism that regulates peripheral $\mathrm{T}$ cell survival.

\section{Methods}

Patient population. Tonsillar tissue was obtained from HIV-infected patients enrolled in ACTG protocol 315 (15). All had baseline CD4 T cell counts of $<300$ cells $/ \mathrm{mm}^{3}$, and were naive to 3TC and protease inhibitors. A washout period of baseline antiretroviral therapy was performed before initiation of HAART, which consisted of ritonavir alone for $10 \mathrm{~d}$, followed by the addition of AZT and 3TC. All three drugs were continued for $48 \mathrm{wk}$. In these HIV-infected patients, tonsillar biopsies and peripheral blood samples were obtained before, and at 1,2,12, and $48 \mathrm{wk}$ after the initiation of HAART. Plasma HIV RNA viral load was measured at those timepoints using the Amplicor system (Roche Diagnostics, Nutley, NJ). Fas susceptibility was studied in a separate cohort of patients antiretroviral naive or failing monotherapy who were commencing HAART with two nucleoside analogues and one protease inhibitor. To further address the molecular mechanism(s) causing HIV-mediated apoptosis in lymphoid tissue, we studied lymphoid tissue from an additional patient who failed therapy (viral load of 5,500 copies/ml) after an initial virological response (undetectable virus) to the administration of HAART (d4T, 3TC, and Saquinavir) for one year.

Analysis of apoptosis in frozen tonsillar specimens. Fresh frozen tonsillar tissue from $\mathrm{HIV}$-infected patients was maintained at $-70^{\circ} \mathrm{C}$ until subsequent use. Frozen sections from tonsillar tissue obtained from non-HIV-infected patients, who underwent routine tonsillectomy, were used as control tissues. Frozen tissues were then cut into $5-\mu \mathrm{m}$ sections, stained for apoptosis using the terminal deoxynucleotide UTP transferase (TUNEL) method, and counterstained with propidium iodide using Apotag direct (Oncor, Gaithersburg, MD) according to the manufacturer's directions. In these experiments, controls for the tissue slides were performed according to the manufacturer's instructions (Oncor). Negative controls consisted of tissue slides that were processed by all the steps with the omission of the terminal deoxynucleotidyl enzyme step. A positive control slide was performed by an extra 10-min incubation, in which the slide was pretreated with $25 \mathrm{U}$ of DNAse I (RNAse free) (Boehringer Mannheim, Indianapolis, IN). Staining proceeded as per the manufacturer's instructions.

Sections were then viewed under a fluorescence filter to detect red (nonapoptotic cells), and green (apoptotic cells) (excitation $\lambda$ 450-490 nm, emission $\lambda 520 \mathrm{~nm}$ long pass). Tissue slides were examined by three independent reviewers, blinded as to the source of tissues, who recorded the number of apoptotic cells in each of the random 10 fields. Data were then analyzed by the Spearman correlation test using SAS software (Cary, NC). In certain experiments (Fig. 1, $B$ and $C$, and Fig. 4), images were obtained using a confocal microscope (Olympus Corp., Lake Success, NY).

Immunostaining for Fas $L$ in frozen tonsillar biopsies. Frozen tonsillar specimens were also analyzed using immunohistochemistry to detect FasL. Tissue sections were rehydrated in PBS and endogenous peroxidase activity blocked. Thereafter, slides were blocked for 15 min with $100 \mu \mathrm{g} / \mathrm{ml}$ human $\mathrm{IgG} 1$, and then with protein block (DAKO Corp., Carpinteria, CA). NOK1 anti-FasL or mouse IgG1 isotype control $(5 \mu \mathrm{g} / \mathrm{ml}$ in $1 \%$ BSA-PBS) was then added to sections for $30 \mathrm{~min}$ (16). Sequentially, biotinylated goat anti-mouse, streptavidin biotin complex, amplification reagent (20\%), and streptavidin peroxidase (all from DAKO Corp.) were added for $15 \mathrm{~min}$ each, with PBS washes in between steps. Antigen detection was done using aminoethyl carbazole (Sigma Chemical Co., St. Louis, MO), and slides counterstained with hematoxylin (Sigma Chemical Co.).

Detection of Fas-mediated apoptosis in peripheral CD4 and CD8
T cells. PBMC from HIV-positive and -negative donors were isolated from buffy coats by density centrifugation using Ficoll Hypaque (Pharmacia LKB Biotechnology Inc., Piscataway, NJ). PBMC underwent plastic adherence for $2 \mathrm{~h}$ in horizontally placed $175-\mathrm{cm}^{2}$ tissue flasks (Costar Corp., Cambridge, MA). $10^{6}$ of nonadherent cells (PBL) were then cultured in wells that had been precoated with $500 \mu \mathrm{l}$ of a $10-\mu \mathrm{g} / \mathrm{ml}$ solution of either M3 agonistic anti-Fas antibody, or isotype control mouse IgG1 (Sigma Chemical Co.) for $2 \mathrm{~h}$ at $37^{\circ} \mathrm{C}$. After washing, cells were cultured for $16 \mathrm{~h}$ in RPMI 1640 media supplemented with $10 \%$ decomplemented FBS (GIBCO BRL, Gaithersburg, MD) plus $2 \mathrm{mmol} /$ liter L-glutamine, $100 \mathrm{U} / \mathrm{ml}$ penicillin $\mathrm{G}$ and $100 \mu \mathrm{g} / \mathrm{ml}$ streptomycin (Whittaker Bioproducts, Walkersville, MD), in a $5 \% \mathrm{CO}_{2}$ atmosphere at $37^{\circ} \mathrm{C}$. For each patient sample analyzed, in addition to the isotype control, PBL from HIV-negative donors were analyzed in parallel, stimulated with either M3 or isotype control as above. Each $\mathrm{HIV}(+)$ donor was matched with a defined $\mathrm{HIV}(-)$ control donor and both were analyzed in parallel at each timepoint of the longitudinal study. Apoptosis was measured using a flow cytometric method previously described (17). PBL were washed in PBS $10 \% \mathrm{Ab}$ serum (GIBCO BRL), and resuspended in PBS $0.1 \%$ azide. Cells were then incubated for $15 \mathrm{~min}$ at $4^{\circ} \mathrm{C}$ with $1 \mu \mathrm{g} / 10^{6}$ cells of both FITC-labeled anti-CD3 monoclonal antibody (Becton Dickinson, San Jose, CA) and phycoerythrin-conjugated anti-CD4 monoclonal antibody (Caltag, San Francisco, CA). Hoechst $33342(2 \mu \mathrm{g} /$ $\mathrm{ml}$; Calbiochem, La Jolla, CA) was added, and cells were incubated for an additional $7 \mathrm{~min}$ at $4^{\circ} \mathrm{C}$. Cells were then washed twice in PBS and resuspended in ice-cold $0.5 \%$ paraformaldehyde in PBS. Flow cytometry was performed using a FACSTAR ${ }^{\circledR}$ (Becton Dickinson) and analysis completed using CELL QUEST ${ }^{\circledR}$ software (Becton Dickinson). 30,000 events were recorded and apoptosis was separately quantitated in the $\mathrm{CD}^{+} / \mathrm{CD}^{+}$and $\mathrm{CD}^{+} / \mathrm{CD}^{-}$populations. Apoptotic cells were quantitated by gating on cells with decreased forward angle light scatter and increased Hoechst-specific fluorescence. To determine whether changes in viral load correlated with changes in $\mathrm{T}$ cell susceptibility to Fas-mediated killing, a Spearman correlation was performed using SAS system software.

To validate the specificity of the TUNEL assay for the detection of tissue apoptosis, we performed additional experiments in which $2 \times$ $10^{6}$ peripheral blood lymphocytes (PBLs)/ml from healthy controls were incubated with $5 \mu \mathrm{g}$ of anti-CD3 (American Tissue Culture Company, Rockville, MD) or IgG (Sigma Chemical Co.) for $45 \mathrm{~min}$ at $4^{\circ} \mathrm{C}$. After washing, cells were transferred to 24-well plates precoated with $20 \mu \mathrm{g}$ of goat anti-mouse antibody (Biosource, Camarillo, CA) in $200 \mu \mathrm{l}$ of $0.05 \mathrm{M}$ carbonate buffer per well. Cells were then harvested, fixed in paraformaldehyde, cytospins performed, and slides stained with TUNEL reagents as above.

\section{Results}

HAART decreases lymphoid tissue apoptosis, which correlates with viral load and peripheral $T$ cells. The specificity of the TUNEL staining was first shown by demonstrating TUNELpositive cells (yellow/green) in both tissue and cytospins of PBL that were treated with DNAse (Figs. $1, A$ and $B$ ). In addition, cultures of PBL treated with anti-CD3 cross-linking antibodies contained more TUNEL-positive cells than PBL cultures treated with IgG1 isotype antibody: $2.25 \pm 0.28$ apoptotic cells per each $40 \times$ objective field versus $0.25 \pm 0.10$, respectively $(P<0.001$, paired $t$ test) (Fig. $1 C)$.

We next studied whether apoptosis was increased in lymphoid tissue from HIV-infected individuals before the initiation of HAART, as compared to that present in HIV-negative controls. The mean number of apoptotic cells present in tonsillar biopsies from three healthy HIV $(-)$ donors per $100 \times$ objective field was $1.60 \pm 0.14$, whereas the mean number of apoptotic cells present in tonsillar biopsies from five $\mathrm{HIV}(+)$ 


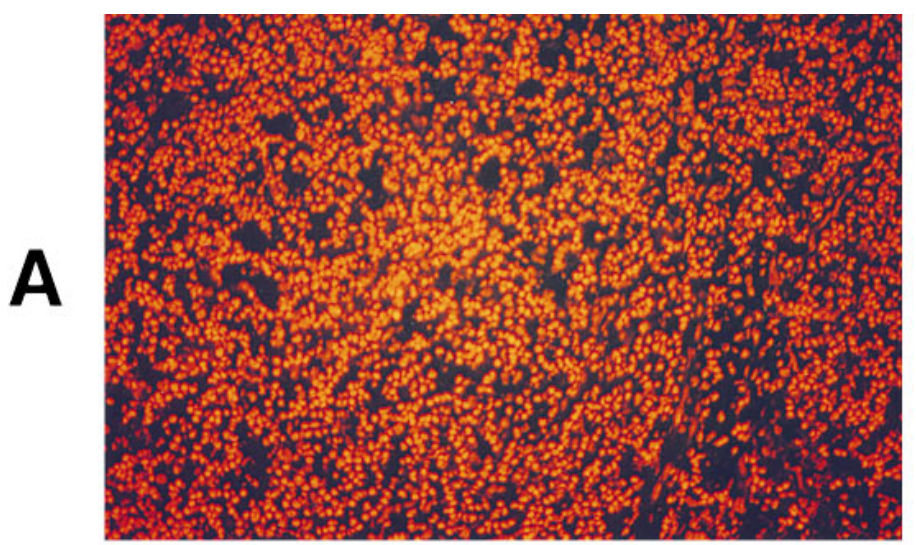

Negative Control

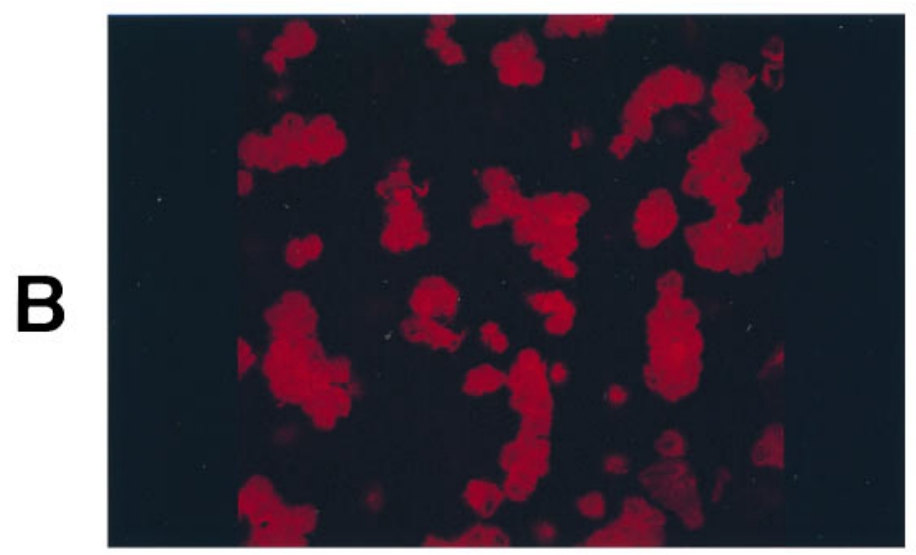

Negative Control

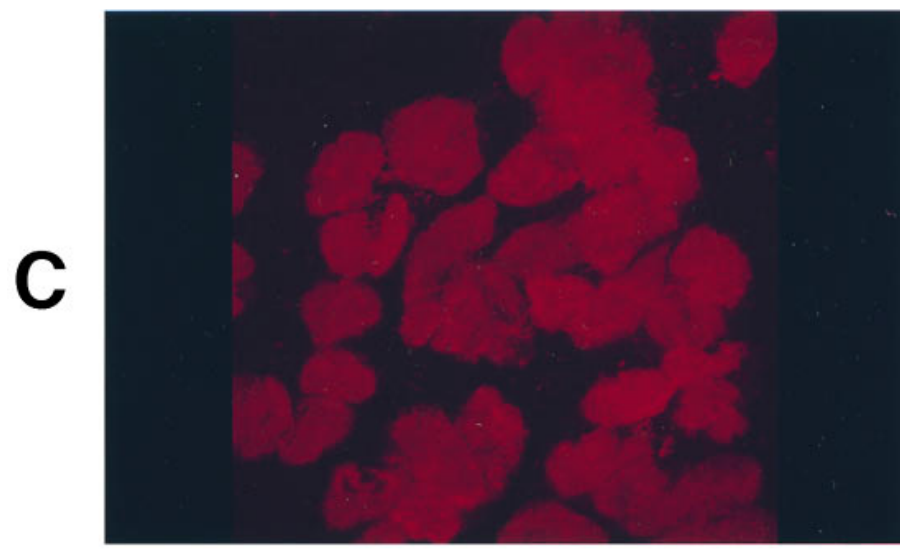

$\lg _{1}$ Cross-linked
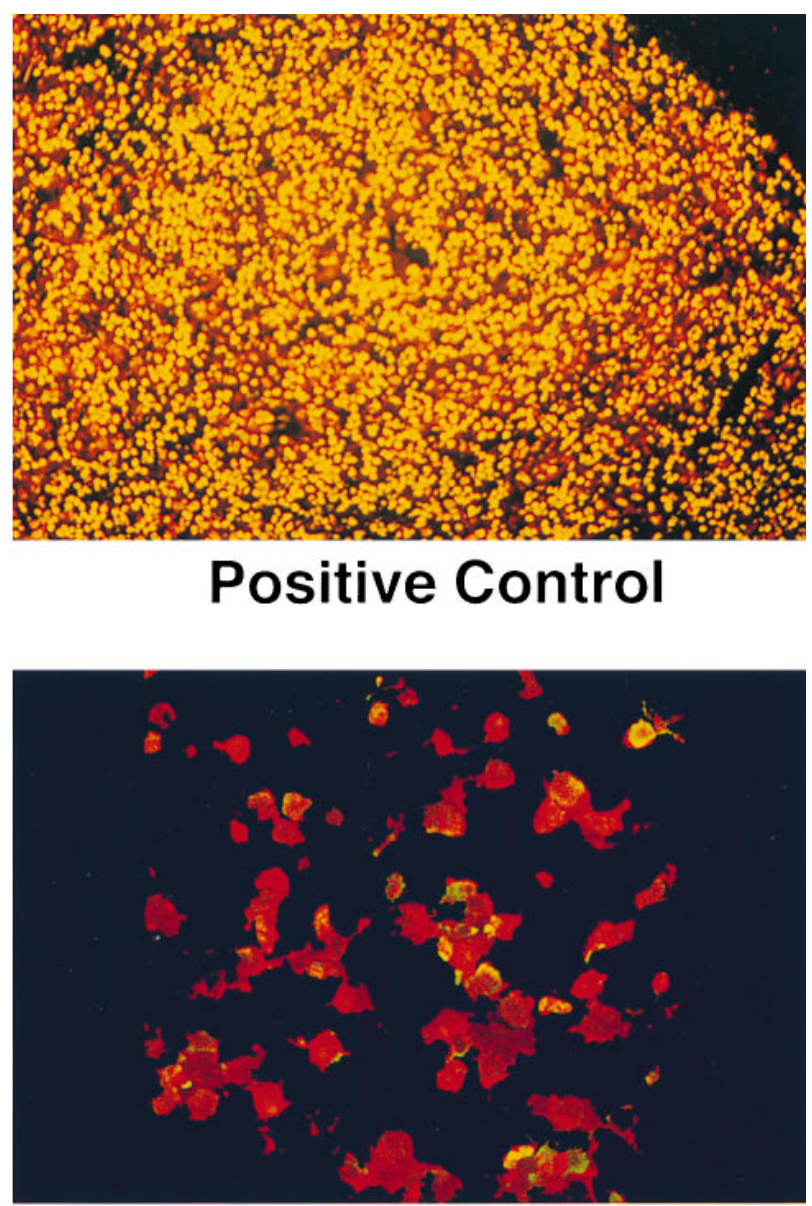

Positive Control

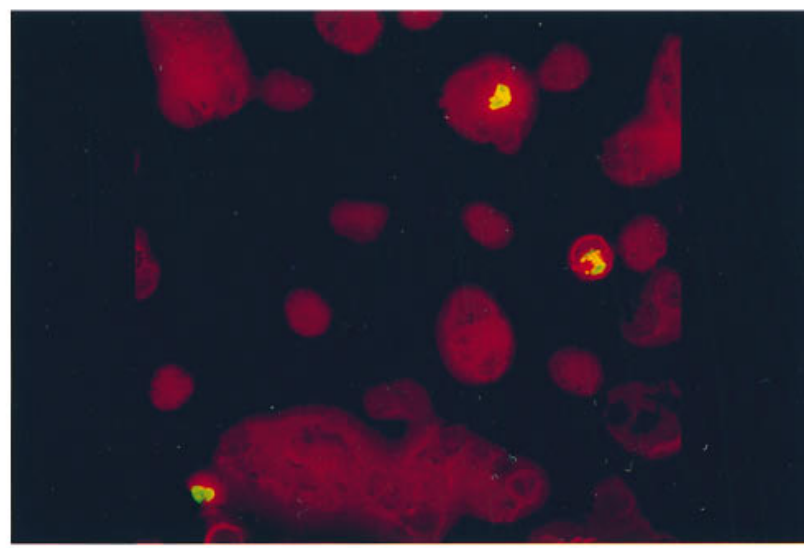

CD3 Cross-linked

Figure 1. Controls for TUNEL staining. Lymphoid tissue from an HIV-infected patient $(A)$ or cytospins of PBL from healthy controls $(B)$ were stained without terminal deoxynucleotide transferase (negative control) or stained after treatment with DNAse (positive control). Yellow/green cells are TUNEL $(+)$ cells. $(C)$ Cytospins of PBL from healthy controls were treated with IgG isotype $(\operatorname{Ig} G)$ or anti-CD3 antibodies $(C D 3)$ followed by goat anti-mouse antibody cross-linking for $72 \mathrm{~h}$.

donors per $100 \times$ objective was $11.20 \pm 0.44(P<0.001)$. A representative experiment is displayed in Fig. 2. The increased number of apoptotic cells in the samples from HIV-infected patients were concentrated in the T cell-rich paracortical areas of lymphoid tissues. Multiple attempts to define the type of cell(s) undergoing apoptosis by immunohistochemistry were unsuccessful due to the technical difficulty of performing double immunofluorescence using TUNEL and T cell immu- 

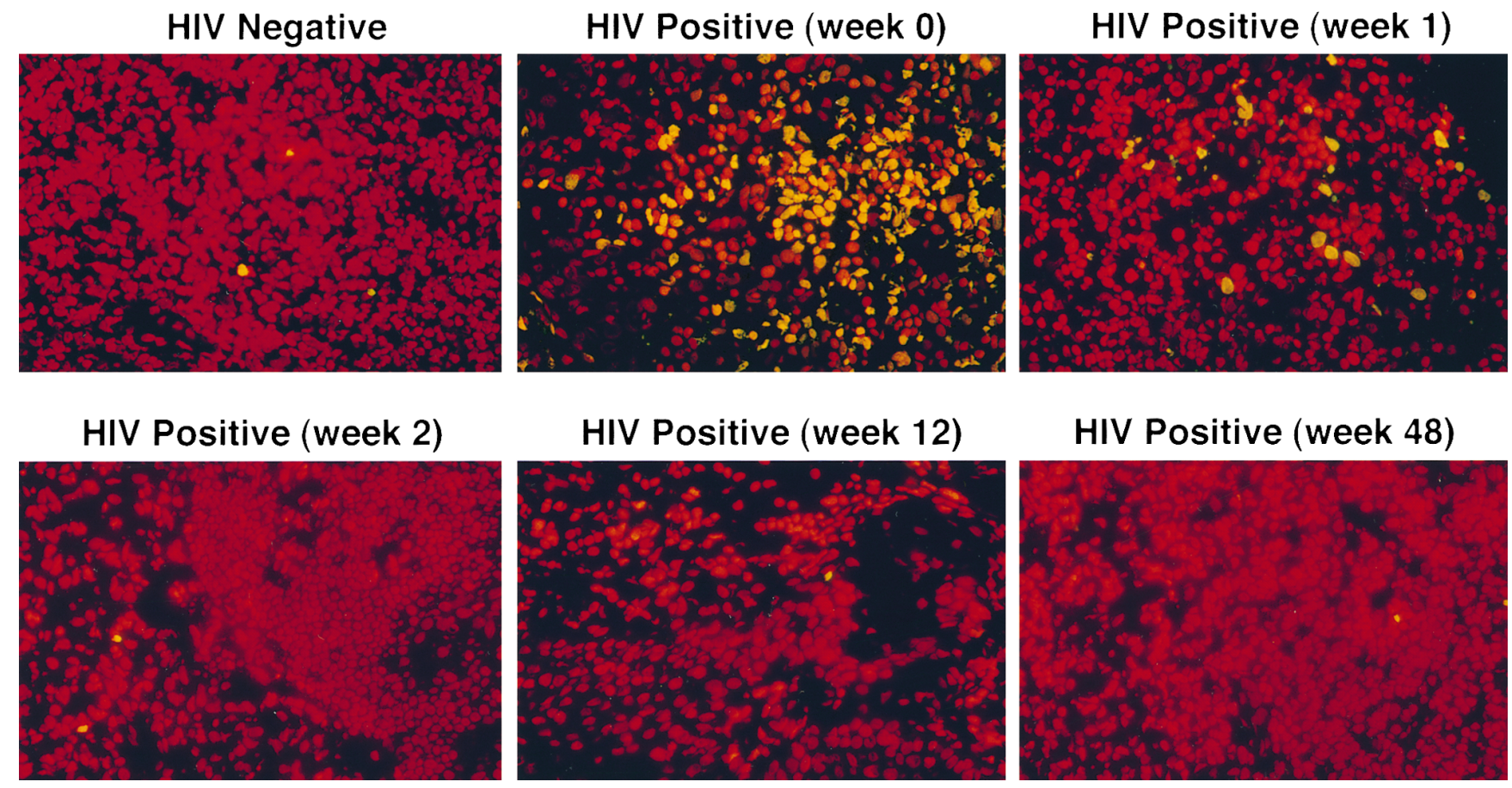

Figure 2. Apoptosis within lymphoid tissue decreases with HAART. Fresh frozen tonsillar biopsies from HIV-positive or -negative patients were analyzed for apoptosis by TUNEL. Representative section of a tonsil from an HIV-negative donor (upper left) and HIV-infected donor (remaining five). For the HIV-infected donor, sections were obtained from sequential biopsies collected before and 1, 2, 12, and 48 wk after the initiation of HAART, and are representative of data from four additional patients.

nophenotyping, although in a parallel study, we have shown by dual staining that apoptotic cells are not tissue macrophages $\left(\mathrm{CD}^{+} 8^{+}\right)(18)$. Importantly, initiation of HAART in these five HIV-infected individuals resulted, within 1-2 wk of therapy, in a significant decrease in the number of apoptotic cells in serial tonsillar biopsies studied ( $P<0.001$, paired $t$ test; Fig. 3), achieving levels of lymphoid tissue apoptosis comparable to those present in specimens from HIV-negative donors (Fig. 2).

In parallel to tissue biopsy specimens, peripheral blood samples obtained from the same HIV-infected patients were analyzed for determination of CD4 and CD8 T cell numbers and viral load. A direct and significant relationship between decreasing lymphoid tissue apoptosis, decreasing HIV load in plasma, and increasing CD4 T cell counts was observed (Fig. 3). In all cases, decreases in tissue apoptosis occurred coincidentally to increases in CD4 T cell counts. An inverse correlation between lymphoid tissue apoptosis and CD4 T cells was confirmed by a Spearman correlation, using data from all five patients $(r=0.706, P<0.01)$. In addition, plasma viral load was observed to decrease in parallel to decreases in tissue apoptosis and increases in peripheral CD4 T cell number $(P<$ 0.001). Of interest, peripheral CD8 $\mathrm{T}$ cell numbers also increased after the initiation of HAART, resulting in a direct correlation between the degree of tissue apoptosis and levels of peripheral CD8 T cells $(r=0.466, P=0.051)$, although to a lesser degree than that observed between the correlation of lymphoid tissue apoptosis and peripheral CD4 T cells (Fig. 3). These results indicate that HAART decreases lymphoid tissue apoptosis in parallel to increasing circulating numbers of peripheral blood $\mathrm{T}$ cells; thereby, identifying lymphoid tissue apoptosis as a direct correlative marker of peripheral CD4, and to a lesser degree, CD8 T cell levels, both as a function of viral load.

Although the preceding section summarizes experiments that demonstrate that effective antiretroviral therapy results in a rapid decrease in tissue apoptosis, we investigated the level of lymphoid tissue apoptosis present in an individual with virologic failure with HAART. The levels of lymphoid tissue apoptosis were comparable in the post-HAART-virological failure biopsy to a pre-HAART biopsy specimen from a patient before initiation of HAART (apoptotic cells per confocal field $19.1 \pm 5.3$ versus $16.7 \pm 3.8$, respectively; Fig. 4). In both situations, the level of tissue apoptosis was significantly increased, when compared to that present in an uninfected individual control (16.7 $\pm 3.8 / 19.1 \pm 5.3$ apoptotic cells/field versus $1.8 \pm 1.9$, respectively; both, $P<0.001$; Fig. 4). This suggests that patients who fail HAART have increased levels of lymphoid tissue apoptosis while on failing antiretroviral regimens.

HAART does not alter the increased levels of FasL in lymphoid tissue from HIV-infected individuals. To investigate the potential molecular mechanisms that could be responsible for tissue apoptosis, and hence, of $\mathrm{T}$ cell turnover, we focused on Fas/FasL interactions before and during HAART. Two separate requirements are needed for a mature $\mathrm{T}$ lymphocyte to undergo apoptosis mediated by Fas/FasL interactions. First, FasL expression needs to be present, and second, the target lymphocyte needs to have been rendered susceptible to FasLtriggered apoptosis (8). To investigate whether either of these two situations was present in these patients, and if so, whether they were modified after HAART, we first focused on FasL 

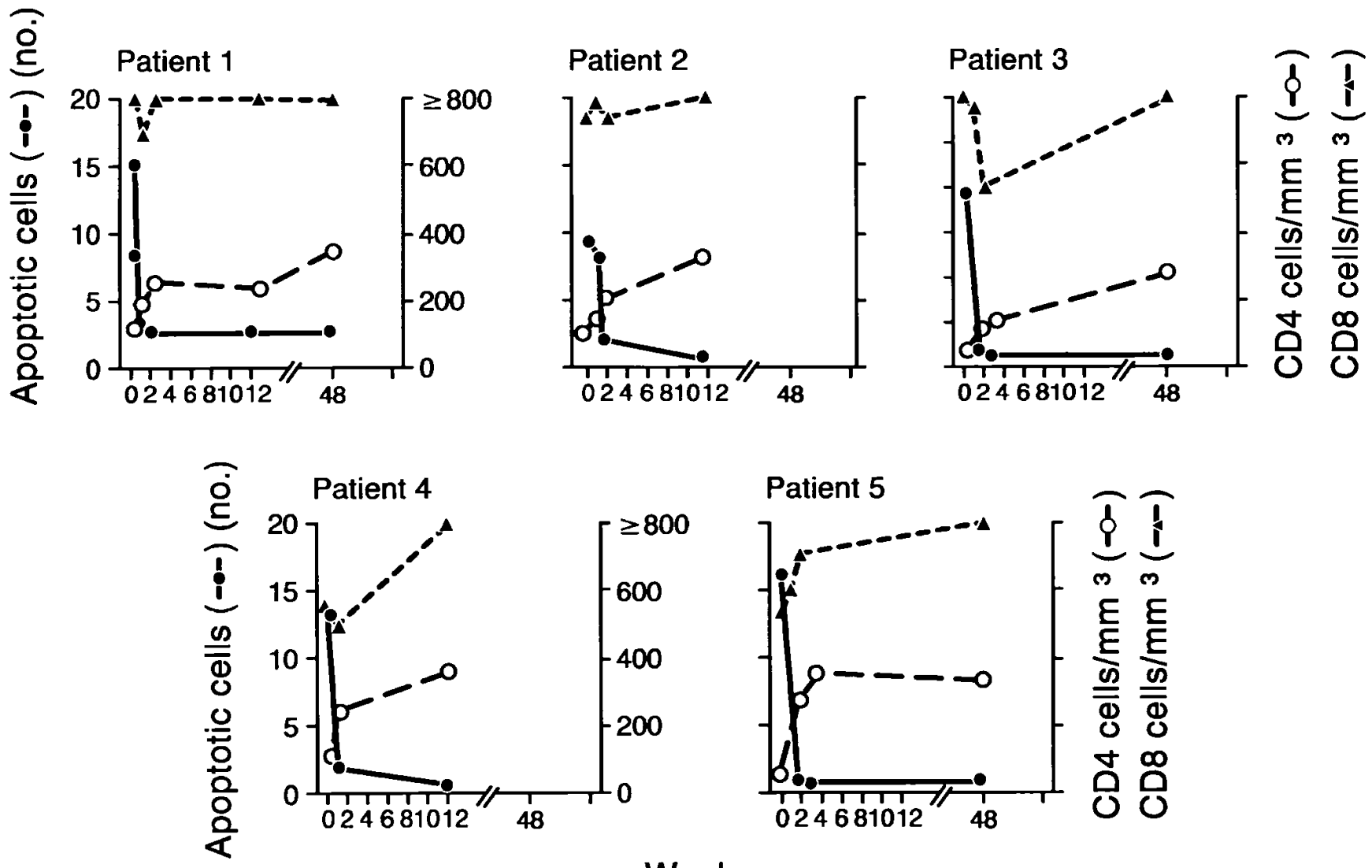

Weeks

Figure 3. Apoptosis within lymphoid tissue correlates with decreased HIV plasma viral load. Data from sequential tonsillar biopsies of the five HIV-infected patients, taken at the timepoints indicated. Left axis depicts number of apoptotic cells per high power field $(\bullet)$, and right axis depicts peripheral blood CD4 T cell counts $(O)$ and CD8 T cell counts $(\boldsymbol{\Delta})$.

expression in sequential tonsillar biopsies obtained before and during HAART from the five HIV-infected patients studied in Fig. 3. The high level of lymphoid tissue FasL expression present in tissue from HIV-infected individuals before HAART was not altered in any of the five patients up to $48 \mathrm{wk}$ of HAART, as shown in a representative patient in Fig. 5. This is in contrast to the significant reduction in the number of apoptotic cells present in the same tissue samples from these individuals or the increase in peripheral CD4 and CD8 T cell numbers observed after initiation of HAART (Figs. 2 and 3). We have previously documented that these FasL-positive cells are CD68+/S100-, although FasL mRNA is also detectable in lymphocytes (18). This suggests that although the enhanced level of FasL expression may participate in lymphoid tissue apoptosis and potentially in T cell depletion, it is not sufficient to explain the impressive recovery of these two parameters after viral reduction by HAART.

$H A A R T$ reduces the susceptibility of peripheral T lymphocytes to Fas-mediated apoptosis in HIV-infected individuals. Recent reports indicate that the recovery of peripheral CD4 and CD8 $\mathrm{T}$ cells that is observed after the initiation of HAART directly correlates with a reduction in various $\mathrm{T}$ cell activation markers (19). Because the degree of $\mathrm{T}$ cell activation correlates with susceptibility to apoptosis (8), and because of reports from several groups including ours, which indicate that CD4, and to a lesser degree, CD8 T cells from HIVinfected individuals, are in an enhanced state of susceptibility to Fas-mediated apoptosis $(12,17,20)$, we investigated whether HAART would result in a modification of the level of susceptibility of peripheral CD4 and CD8 T cells to Fas-dependent apoptosis.

Before initiation of antiretroviral therapy, the mean proportion of CD4 $\mathrm{T}$ cells that underwent Fas-mediated apoptosis was $26.3 \pm 4.1 \%$ in the HIV-infected group, as compared to $10.9 \pm 1.5 \%$ in the HIV-negative control group $(P=0.005$, paired $t$ test). After the initiation of HAART, Fas-mediated apoptosis in the CD4 T cells from HIV-infected patients significantly declined $(P=0.01$, paired $t$ test), achieving a similar low level of apoptosis at the last timepoint of sampling (Fig. 6), as observed among CD4 T cells obtained from matched HIVnegative patients (HIV-infected $8.9 \pm 2.3 \%$; HIV-negative $7.7 \pm$ $1.8 \%$. In parallel to these findings, in all six HIV-infected patients HAART induced a prompt decrease in plasma HIV viral load, which directly correlated with the decreases in Fas sensitivity ( $r=0.63, P=0.018$, Spearman correlation). Of interest, in patient No. 6 , the reduction of both plasma viral load and CD4 $\mathrm{T}$ cell susceptibility to Fas-mediated apoptosis was reversed after discontinuing combination HAART; or as noted in patients Nos. 1 and 2, intercurrent infectious complications occurring at weeks 8 and 3 of HAART, respectively, 
HIV negative

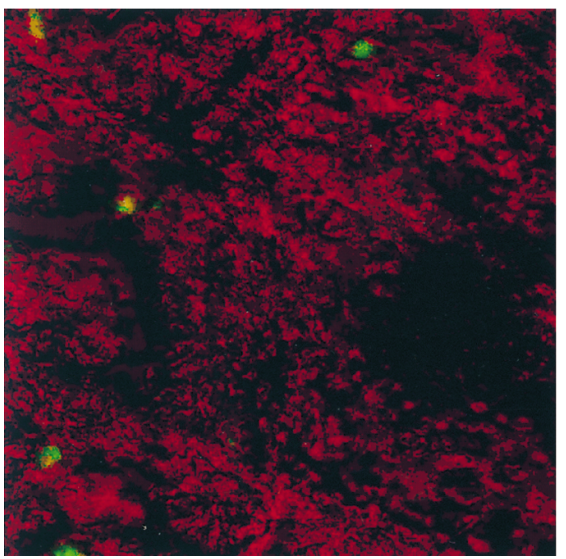

HIV pre-treatment

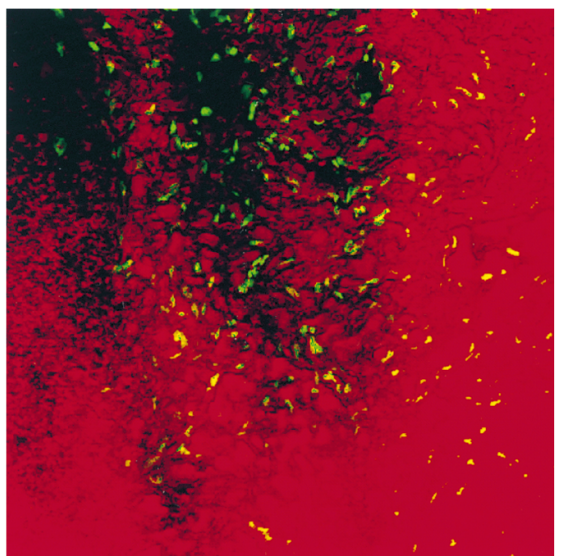

HIV treatment failure

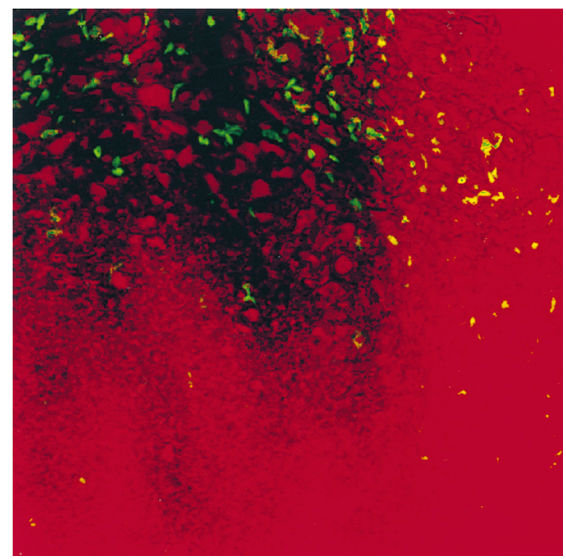

Figure 4. Cessation of HAART results in rapid return of high levels of tissue apoptosis. Tonsillar tissues from an HIV-negative individual or from an HIV-positive individual obtained before HAART treatment or after treatment failure with HAART were examined by TUNEL staining.

resulted in a transient and reversible increase in susceptibility of CD4 T cells to Fas-mediated apoptosis (Fig. 6).

Analysis of susceptibility to Fas-mediated apoptosis was also performed on the CD8 T cell subpopulation and indicated that HAART also decreased the mean proportion of CD8 T cells that underwent Fas-mediated apoptosis $(32.6 \pm 15.0 \%$ pretreatment, versus $14.0 \pm 7.3 \%$ posttreatment $P=0.031$ ), which correlated with a rebound in the levels of peripheral CD8 T cells (Fig. 6). Altogether, these results indicate that circulating peripheral $\mathrm{T}$ cells are in an enhanced state of susceptibility to Fas-mediated apoptosis before initiation of HAART, which directly correlates with viral load and normalizes in response to effective suppression of HIV replication.

\section{Discussion}

This study provides novel evidence that the increased level of apoptosis observed in lymphoid tissue and a defined molecular mechanism identified to play a role in peripheral $\mathrm{T}$ cell homeostasis are a function of viral load. Taking advantage of the combination of potent antiretroviral agents, a dynamic correlation between lymphoid tissue apoptosis and susceptibility to Fas-mediated death with viral load and peripheral T cell numbers was established.

Whereas multiple previous studies have suggested that apoptosis participates in CD4 T cell depletion in HIV-infected individuals based on results from in vitro models, the rele-

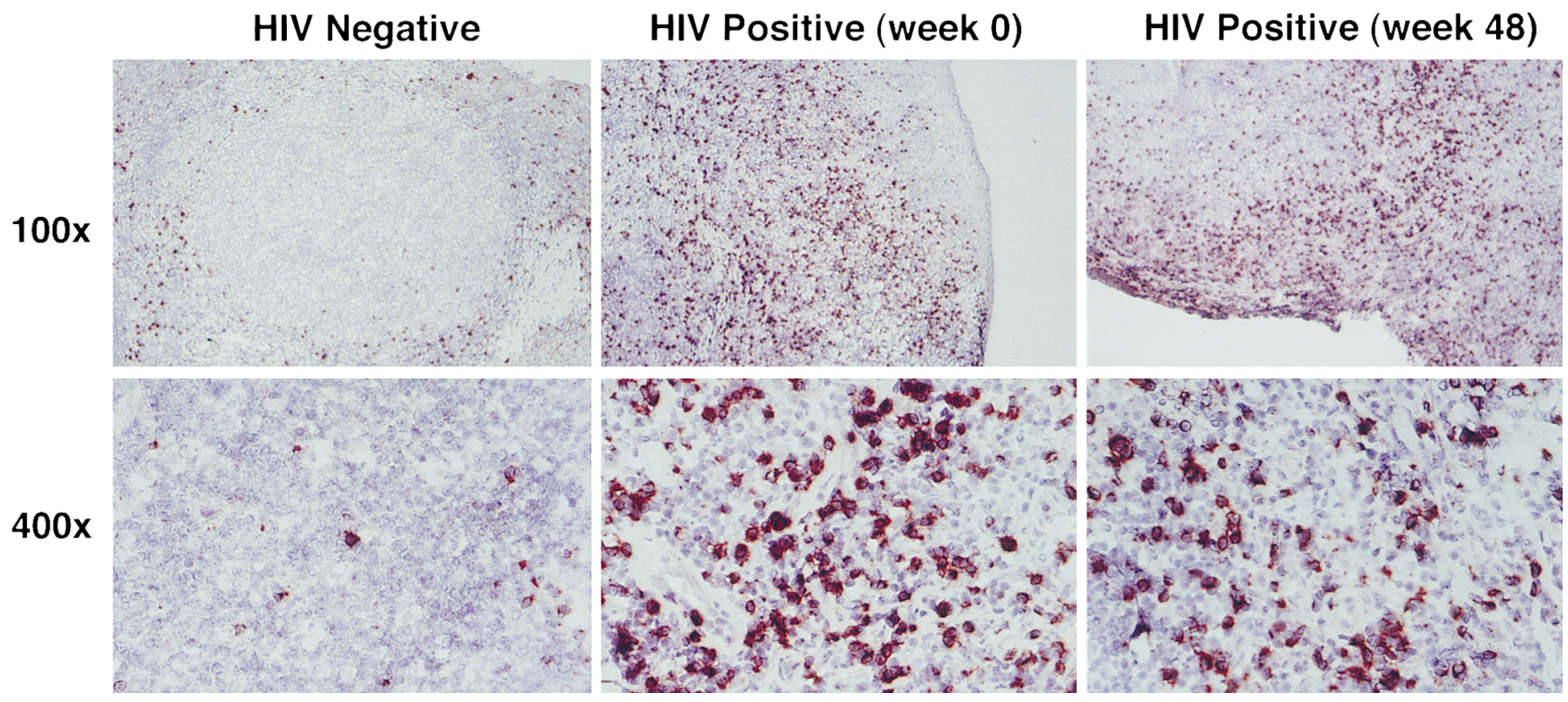

Figure 5. HAART does not alter tissue FasL in lymphoid tissue from HIV-infected patients. Tonsillar sections from an HIV-negative patient (left), and an HIV-infected patient before (middle) and $48 \mathrm{wk}$ after (right) the initiation of HAART were stained for FasL (red), as viewed under $100 \times$ (upper row) and under $400 \times$ (lower row). 

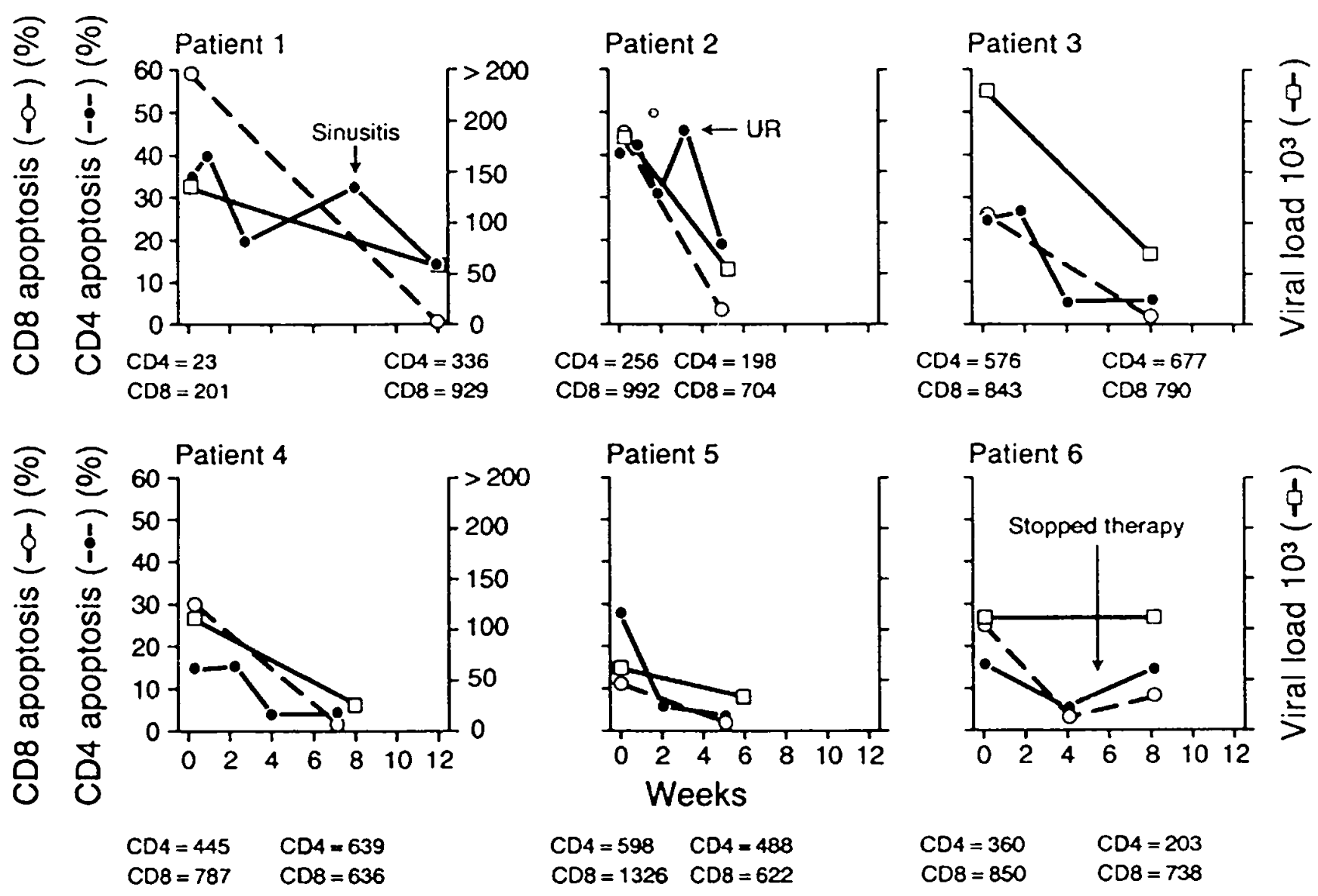

Figure 6. HAART decreases the susceptibility of peripheral CD4 and CD8 T cells from HIV-infected individuals to Fas-mediated apoptosis. Peripheral blood samples from HIV-infected patients were analyzed for plasma viral load in copies/ml and for CD4 and CD8 T cell sensitivity to Fas-mediated apoptosis before and after the initiation of HAART. Data from six patients is presented individually for CD4 T cell Fas sensitivity (๑), CD8 T cell sensitivity ( $\bigcirc$; left axis), and for viral load plotted in open squares (right axis). Values of peripheral CD4 and CD8 T cells preand at the last timepoint of HAART are indicated at the bottom of each patient's graft. Two patients, (Nos. 1 and 2) had infections with sinusitis and upper respiratory tract infection at the timepoints indicated. Patient No. 6 stopped taking HAART at the timepoint indicated. The mean percent of peripheral CD4 T cell apoptosis from HIV-negative controls was $3.7 \% \pm 0.3$ for isotype-treated cells, and $8.9 \% \pm 1.5$ for anti-Fas antibodies-treated cells.

vance of the studies to the pathogenesis of HIV infection in vivo has remained inconclusive $(2,9,10,21-23)$. The demonstration that, within the same HIV-infected individual, the degree of lymphoid tissue apoptosis is significantly reduced after antiretroviral-driven decreases in HIV viral load and increases in peripheral $\mathrm{T}$ cells, highlights the potential relevance of this form of death as a mechanism involved in the enhanced depletion of peripheral $\mathrm{T}$ lymphocytes during the course of this infection. Unfortunately, due to current technical limitations, it is not possible to determine exactly the identity of those cells that are undergoing apoptosis, despite their location in the $\mathrm{T}$ cell-rich area of lymphoid tissue. However, in a study by Muro-Cacho et al., in which cell extracts were isolated from lymph nodes from HIV-infected individuals and analyzed in cell suspensions, it was demonstrated that a significant degree of cell apoptosis was present within both CD4 and CD8 T lymphocytes fractions (24). If such results are applied to our observations, it implies that at least both types of T cell phenotype are undergoing apoptosis in lymphoid tissues due to HIV- related stimuli, and thus, reduction in viral load results in a decrease in tissue lymphocyte apoptosis.

The fact that not only CD4 but also CD8 T cell apoptosis may be present in lymphoid tissue in vivo (24), or ex vivo after PBL activation with mitogens $(9,10,25-28)$, has led to the rejection of apoptosis as a putative mechanism involved in CD4 $\mathrm{T}$ cell depletion in HIV infection. Alternatively, in vivo, or ex vivo CD8 T cell death in the context of HIV infection has been regarded by those investigators that support a role of apoptosis in causing HIV pathogenesis as nonspecific. The results of our study may conciliate both arguments, as it indicates that a prompt reduction of HIV replication directly correlates not only with a decrease of tissue apoptosis, but also with an increase in both CD4 and CD8 T lymphocytes in peripheral blood. This reflects that HIV-related mechanisms (viral proteins, cytokines, chemokines) may be targeting not only CD4, but also, albeit to a different degree, CD8 T cells, thus leading to a chronic state of peripheral $\mathrm{T}$ cell activation that ultimately marks the lymphocyte to undergo apoptosis. 
Although the efforts at understanding the pathogenesis of HIV infection have focused on CD4 T cell depletion, it is now clearly demonstrated that CD8 T cells are also eliminated, especially during the latter course of HIV infection (29). Therefore, the virus-induced hyperactivation of these two lymphocyte populations could explain their elimination by defined molecular mechanisms that mediate lymphocyte death. Enhanced $\mathrm{T}$ cell apoptosis, together with other HIV-related mechanisms such as impaired $\mathrm{T}$ cell homeostasis, premature lymphocyte senescence, thymic dysregulation, lymphocyte trapping in infected lymph nodes, direct HIV cytopathicity, or immune elimination of infected lymphocytes (29-35), could in combination contribute to $\mathrm{T}$ cell depletion during different stages of HIV infection. Based on our data indicating a prompt decrease in tissue apoptosis contemporary with the initiation of HAART, enhanced apoptosis of abnormally activated T lymphocytes is a potential cause contributing to $\mathrm{T}$ cell depletion. This would explain how HAART exerts a beneficial effect on T cell homeostasis by reducing apoptosis (36). The consequences of the additional mechanisms mentioned above, such as premature senescence of T lymphocytes or thymic dysregulation, may require additional time beyond the first few weeks after HAART initiation for CD4, and, potentially, for CD8 T cells to reach physiological levels.

This longitudinal clinical study has also provided an in vivo example of how the dynamics of defined molecular mechanisms controlling susceptibility of T cells to apoptosis are dependent on the level of HIV replication. Although the reduction of the susceptibility to Fas-dependent apoptosis of CD4 and CD8 T cells after reduction in viral load was not unexpected, the fact that the already enhanced levels of FasL expression in lymphoid tissue from HIV-infected patients was not modified by prolonged HAART was surprising. We postulate, based on in vitro data $(17,18)$, that modifying one of the two parameters that control Fas/FasL-mediated lymphocyte apoptosis is sufficient to decrease an enhanced level of lymphocyte death. As was the case in this study, reducing the susceptibility of $\mathrm{T}$ cells to Fas-mediated apoptosis was sufficient. Nevertheless, the high and persistent level of FasL expression in macrophages within lymphoid tissue of these individuals is intriguing and warrants further study. Previous data has demonstrated that a minority of lymph node macrophages are infected with HIV (37-38), thereby suggesting that direct HIV infection of these cells is not directly responsible for the enhanced FasL expression in the majority of macrophages in lymphoid tissue from HIV-infected individuals. More likely, FasL expression may depend on indirect HIV-related mechanisms such as soluble HIV proteins, cytokines, or chemokines. The fact that detectable HIV proviral DNA and RNA is still found in lymph nodes after at least six mo of HAART, the observation of a rapid reappearance of HIV RNA after cessation of successful suppression of HIV by antiretrovirals, and the recovery of replication competent virus despite prolonged suppression of plasma viremia (39-42), suggests that a low grade of HIV replication in cell reservoirs may suffice to maintain FasL expression in the micro environment of lymphoid tissue. The importance of macrophage-associated FasL and its upregulation, presumably by HIV-dependent mechanisms, in mediating the death of Fas-susceptible $\mathrm{T}$ lymphocytes, has been previously shown by our group using in vitro models (17). In fact, in those studies, it was possible to demonstrate that macrophages induced the selective death of CD4 and not CD8 T cells from HIV-infected individuals. The selectivity of cell-cell interaction such as macrophage-CD4 T cells in vivo in lymphoid tissue could potentially explain the preferential elimination of CD4, even though both CD4 and CD8 T cells are susceptible to Fas-mediated apoptosis.

In summary, our studies suggest a model in which HIV infection results in an enhanced state of $\mathrm{T}$ cell activation that leads to an enhanced susceptibility to Fas-mediated apoptosis, and an increase of FasL expression in lymphoid tissue, mechanisms which suggest an enhanced deletion of activated CD4 and CD8 T cells. Results from the current report lay the foundation for future work evaluating the role of specific inhibitors of FasL regulation, Fas/FasL interaction, or Fas signal transduction, as well as understanding the molecular mechanisms whereby HIV or its related products lead to the aberrant activation of mature $\mathrm{T}$ lymphocytes.

\section{Acknowledgments}

The authors are indebted to the patients who donated specimens for this work, and to the medical professionals responsible for managing their care. We acknowledge the exceptional secretarial help provided by Teresa Hoff and the helpful discussions provided by members of the Paya laboratory. We also wish to thank Dr. Jim Chmiel for the performance of tonsillar biopsies at CWRU, Cleveland, $\mathrm{OH}$.

A.D. Badley is supported by grants from Physicians Services Incorporated Foundation and is a scholar of the Doris Duke Charitible Foundation.

\section{References}

1. Perelson, A.S., A.U. Neumann, M. Markowitz, J.M. Leonard, and D.D. Ho. 1996. HIV-1 dynamics in vivo: virion clearance rate, infected cell life-span, and viral generation time. Science. 271:1582-1586.

2. Badley, A.D., D.H. Dockrell, and C.V. Paya. 1997. Apoptosis in AIDS In Apoptosis Pharmacological Implications and Therapeutic Opportunities. S.H. Kaufmann, editor. Academic Press, San Diego, CA. 41:271-289.

3. Dhein, J., H. Walczak, C. Baumler, K.-M. Debatin, and P.H. Krammer. 1995. Autocrine T-cell suicide mediated by APO-1/Fas (CD95). Nature. 373: $438-441$.

4. Brunner, T., R.J. Mogil, D. LaFace, N.J. Yoo, A. Mahboubi, F. Echeverri, S.J. Martin, W.R. Force, D.H. Lynch, C.F. Ware, and D.R. Green. 1995. Cell-autonomous Fas (CD95)/Fas-ligand interaction mediates activation-induced apoptosis in T-cell hybridomas. Nature. 373:441-444.

5. Alderson, R., T.W. Tough, T. Davis-Smith, S. Braddy, B. Falk, K.A Schooley, R.G. Goodwin, C.A. Smith, F. Ramdsdell, and D.H. Lynch. 1995. Fas ligand mediates activation-induced cell death in human T lymphocytes. J. Exp. Med. 181:71-77.

6. Sytwu, K., R.S. Liblau, and H.O. McDevitt. 1996. The roles of Fas/APO-1 (CD95) and TNF in antigen-induced programmed cell death in T cell receptor transgenic mice. Immunity. 5:17-30.

7. Zheng, L., G. Fisher, R.E. Miller, J. Peschon, D.H. Lynch, and M.J. Lenardo. 1995. Induction of apoptosis in mature $\mathrm{T}$ cells by tumor necrosis factor. Nature. 377:348-351.

8. Boise, L.H., and C.B. Thompson. 1995. Hierarchical control of lymphocyte survival. Science. 274:67-68.

9. Groux, H., G. Torpier, D. Monté, Y. Mouton, A. Capron, and J.C. Ameisen. 1992. Activation-induced death by apoptosis in $\mathrm{CD}^{+} \mathrm{T}$ cells from human immunodeficiency virus-infected asymptomatic individuals. J. Exp. Med. 175:331-340.

10. Meyaard, L., S.A. Otto, R.R. Jonker, M.J. Mijnster, R.P. Keet, and F. Miedema. 1992. Programmed death of T cells in HIV-1 infection. Science. 257: 217-219.

11. Oyaizu, N., T.W. McCloskey, M. Coronesi, N. Chirmule, V.S. Kalyanaraman, and S. Pahwa. 1993. Accelerated apoptosis in peripheral blood mononuclear cells (PBMCs) from human immunodeficiency virus type-1 infected patients and in CD4 cross-linked PBMCs from normal individuals. Blood. 82: 3392-3400.

12. Katsikis, P.D., E.S. Wunderlich, C.A. Smith, L.A. Herzenberg, and L.A Herzenberg. 1995. Fas antigen stimulation induces marked apoptosis of T lymphocytes in human immunodeficiency virus-infected individuals. J. Exp. Med. 181:2029-2036.

13. Laurence, J. 1995. CD4 ${ }^{+}$and $\mathrm{CD}^{+}{ }^{+}$T lymphocyte activation in HIV in- 
fection. Implications for immune pathogenesis and therapy. Adv. Exp. Med. Biol. 374:1-15.

14. Kinter, A.L., M. Ostrowski, D. Golette, A. Oliva, D. Weissman, K. Gantt, E. Hardy, R. Jackson, L. Ehler, and A.S. Fauci. 1996. HIV replication in $\mathrm{CD}^{+}{ }^{+} \mathrm{T}$ cells of HIV-infected individuals is regulated by a balance between the viral suppressive effects of endogenous $\beta$-chemokines and the viral inductive effects of other endogenous cytokines. Proc. Natl. Acad. Sci. 93:14076-14081.

15. Lederman, M., E. Connick, A. Landay, H. Kessler, D. Kuritzkes, M. St. Clair, L. Fox, M. Heath-Chiozzi, F. Rousseau, and J. Spritzler. 1997. Partial immune reconstitution after 12 weeks of HAART (AZT, 3TC, Ritonavir) preliminary results of ACTG 315. 4th Conference on Retroviruses and Opportunistic Infections, Jan 22-26. Washington, D.C. (Abstr. LB13.)

16. Kayagaki, N., A. Kawasaki, T. Ebata, H. Ohmoto, S. Ikeda, S. Inoue, K. Yoshino, K. Okurmura, and H. Yagita. 1995. Metalloproteinase-mediated release of human Fas ligand. J. Exp. Med. 182:1777-1783.

17. Badley, A.D., D. Dockrell, M. Simpson, R. Schut, D.H. Lynch, P. Leibson, and C.V. Paya. 1997. Macrophage-dependent apoptosis of $\mathrm{CD}^{+} \mathrm{T}$ lymphocytes from HIV-infected individuals mediated by FasL and tumor necrosis factor. J. Exp. Med. 185:55-64.

18. Dockrell, D.H., A.D. Badley, C.J. Heppelmann, S. Ziesmer, H. Yagita, D.H. Lynch, P.C. Roche, P.J. Leibson, and C.V. Paya. 1998. The expression of Fas ligand by differentiated macrophages and its upregulation by HIV infection. J. Clin. Invest. 101:2394-2405.

19. Kelleher, A., A. Carr, J. Zaunders, and D.A. Cooper. 1996. Alterations in the immune response of human immunodeficiency virus (HIV)-infected subjects treated with an HIV-specific protease inhibitor, ritonavir. J. Infect. Dis. 173:321-329.

20. Desbarats, J., J.H. Freed, P.A. Campbell, and M.K. Newell. 1996. Fas (CD95) expression and death-mediating function are induced by CD4 crosslinking on CD4 ${ }^{+}$T cells. Proc. Natl. Acad. Sci. 93:11014-11018.

21. Badley, A.D., J.A. McElhinny, P.J. Leibson, D.H. Lynch, M.R. Alderson, and C.V. Paya. 1996. Upregulation of Fas ligand expression by human immunodeficiency virus in human macrophages mediates apoptosis of uninfected T lymphocytes. J. Virol. 70:199-206.

22. Laurent-Crawford, A.G., B. Krust, Y. Riviére, C. Desgranges, S. Muller, M.P. Kieny, C. Dauguet, A.G. Hovanessian. 1993. Membrane expression of HIV envelope glycoproteins triggers apoptosis in CD4 cells. AIDS Res. Hum. Retroviruses. 9:761-763.

23. Yang, Y., J. Bailey, M.S. Vacchio, R. Yarchoan, and J.D. Ashwell. 1995. Retinoic acid inhibition of ex vivo human immunodeficiency virus-associated apoptosis of peripheral blood cells. Proc. Natl. Acad. Sci. 92:3051-3055.

24. Muro-Cacho, C.A., G. Pantaleo, and A.S. Fauci. Analysis of apoptosis in lymph nodes of HIV-infected persons. Intensity of apoptosis correlates with the general state of activation of the lymphoid tissue and not with stage of disease or viral burden. J. Immunol. 154:5555-5566.

25. Gougeon, M.L., S. Garcia, J. Heeney, R. Tschopp, H. Lecoeur, D. Guetard, V. Rame, C. Dauguet, and L. Montagnier. 1993. Programmed cell death in AIDS-related HIV and SIV infections. AIDS Res. Hum. Retroviruses. 9:553-563.

26. Sarin, A., M. Clerici, S.P. Blatt, C.W. Hendrix, G.M. Shearer, and P.A. Henkart. 1994. Inhibition of activation-induced programmed cell death and restoration of defective immune responses of $\mathrm{HIV}^{+}$donors by cysteine protease inhibitors. J. Immunol. 143:862.

27. Gougeon, M.-L., H. Lecour, A. Dulioust, M.-G. Enouf, M. Crouvoisier, C. Goujard, T. Debord, and L. Montagnier. 1996. Programmed cell death in pe- ripheral lymphocytes from HIV-infected persons. J. Immunol. 156:3509-3520.

28. Estaquier, J., T. Idzoiorek, F. de Bels, F. Barré-Sinoussi, B. Hurtrel, A.M. Aubertin, A.Venet, M. Mehtali, E. Muchmore, P. Michel, Y. Mouton, M. Girard, and J.C. Ameisen. 1994. Programmed cell death and AIDS: significance of T-cell apoptosis in pathogenic and nonpathogenic primate lentiviral infections. Proc. Natl. Acad. Sci. 91:9431-9435.

29. Margolick, J.B., A. Munoz, A.D. Donnenberg, L.P. Park, N. Galai, J.V. Giorgi, M.R. O'Gorman, and J. Ferbas. 1995. Failure of T-cell homeostasis preceding AIDS in HIV-1 infection. The Multicenter AIDS Cohort Study. Nat. Med. 1:674-680.

30. Su, L., H. Kaneshima, M. Bonyhadi, S. Salimi, D. Kraft, L. Rabin, and J.M. McCune. 1995. HIV-1-induced thymocyte depletion is associated with indirect cytopathicity and infection of progenitor cells in vivo. Immunity. 2:25-36.

31. Wolthers, K.C., G. Bea, A. Wisman, S.A. Otto, A.-M. de Roda Husman, N. Schaft, F. de Wolf, J. Goudsmit, R.A. Coutinho, A.G. van der Zee, L. Meyaard, and F. Miedema. 1996. T cell telomere length in HIV-1 infection: no evidence for increased CD4 ${ }^{+}$T cell turnover. Science. 274:1543-1547.

32. Lifson, J.D., G.R. Reyes, M.S. McGrath, B.S. Stein, and E.G. Engleman. 1986. AIDS retrovirus induced cytopathology: giant cell formation and involvement of CD4 antigen. Science. 232:1123-1127.

33. Nixon, D.F., A.R. Townsend, J.G. Elvin, C.R. Rizza, J. Gallwey, and A.J. McMichael. 1988. HIV-1 gag-specific cytotoxic T lymphocytes defined with recombinant vaccinia virus and synthetic peptides. Nature. 336:484-487.

34. Haase, A.T., K. Henry, M. Zupancic, G. Sedgewick, R.A. Faust, H. Melroe, W. Cavert, K. Gebhard, K. Staskus, Z.Q. Zhang, et al. 1996. Quantitative image analysis of HIV-1 infection in lymphoid tissue. Science. 274:985-989.

35. Walker, B.D., S. Chakrabarti, B. Moss, T.J. Paradis, T. Flynn, A.G Durno, R.S. Blumberg, J.C. Kaplan, M.S. Hirsch, and R.T. Schooley. 1987. HIV-specific cytotoxic T lymphocytes in seropositive individuals. Nature. 328: 345-348.

36. Autran, B., G. Carcelain, T.S. Li, C. Blanc, D. Mathez, R. Tubiana, C Katlama, P. Debré, and J. Leibowitch. 1997. Positive effects of combined antiretroviral therapy on $\mathrm{CD}^{+} \mathrm{T}$ cell homeostasis and function in advanced HIV disease. Science. 277:112-116.

37. Embretson, J., M. Zupancic, J.L. Ribas, A. Burke, P. Racz, K. TennerRacz, A.T. Haase. 1993. Massive covert infection of helper T lymphocytes and macrophages by HIV during the incubation period of AIDS. Nature. 362:359-362.

38. Chun, T.-W., L. Carruth, D. Finzi, X. Shen, J.A. DiGiuseppe, H. Taylor, M. Hermankova, K. Chadwick, J. Margolick, T.C. Quinn, Y.-H. Kuo, R. Brookmeyer, M.A. Zeiger, P. Barditch-Crovo, and R.F. Siliciano. 1997. Nature. 387: $183-188$.

39. Cavert, W., S.D.W. Notermans, K. Staskus, S.W. Wietgrefe, M. Zupancic, K. Gebhard, K. Henry, Z.-Q. Zhang, R. Mills, H. McDade, J. Goudsmit, S.A. Danner, and A.T. Haase. 1997. Kinetics of response in lymphoid tissues to antiretroviral therapy of HIV-1 infection. Science. 276:960-964.

40. Pantaleo, G. 1997. How immune-based interventions can change HIV therapy. Nat. Med. 3:483-486.

41. Wong, J.K., M. Hezareh, H.F. Günthard, D.V. Havlir, C.C. Ignacio, C.A. Spina, and D.D. Richman. 1997. Recovery of replication-competent HIV despite prolonged suppression of plasma viremia. Science. 278:1291-1295.

42. Finzi, D., M. Hermankova, T. Pierson, L.M. Carruth, C. Buck, R.E. Chaisson, T.C. Quinn, K. Chadwick, J. Margolick, R. Brookmeyer, et al. 1997. Identification of a reservoir for HIV-1 in patients on highly active antiretroviral therapy. Science. 278:1295-1300. 